\title{
PERFORMANCE OF WHITE CLOVER LINES ON NEW ZEALAND HILL COUNTRY
}

\author{
W. M. Williams, J. R. Caradus \\ Grasslands Division, DSIR, Palmerston N orth
}

\section{Abstract}

Eighty-two white clover lines from overseas and 13 hill country collections from within New Zealand have been examined on a hill country site for their persistence and production potential under sheep grazing on infertile soils. By the third year of the trial only seven lines were equal to or better than Huia. These included only two overseas lines (one cultivar from France ('Crau') and a line from New Hampshire, U.S.A.) and five of the 13 collections from New Zealand hill country. This is considered to be a strong argument for the use of New Zealand material in breeding white clover for New Zealand hill country conditions.

\section{INTRODUCTION}

APProximately one-third of New Zealand consists of relatively infertile, unploughable hill country dominated by browntop and other low-producing grasses, often with a very low legume content. Suckling (1965) has stressed the fundamental requirement for increasing the quantity and quality of perennial legumes in hill pastures if production is to be increased. White clover (Trifolium repens L.) thrives best under high fertility, although it grows reasonably well at moderately low fertility and on relatively acid soils. In order to thrive in hill country pastures, a white clover cultivar is required which is well adapted to both sheep grazing and low soil phosphate levels.

Accordingly, 98 white clover lines were evaluated on a hill country site for their ability to persist and produce under sheep grazing on an infertile soil.

\section{EXPERIMENTAL}

The experimental material consisted of 82 overseas lines and cultivars of white clover from 22 countries (Table 1), 16 lines of New Zealand origin, and four lines of Caucasian clover, Trifolium ambiguum Bieb. The New Zealand lines were the two commercial cultivars ('Grasslands Huia' and 'Grasslands Pitau'), an experimental hybrid line (Ladino X Pitau), and 13 seed lines derived from plant collections from hill country farms, including 
three from Ballantrae, the hill country research station of Grasslands Division, in the southern Ruahine Range, near Woodville.

Plants were grown from seed in a glasshouse for 2 months befdre planting in May 1975 at Ballantrae. The trial sites were a north-facing (sunny) and a south-facing (shady) slope of approximately 30". The soil was a Makotuku hill soil (Rijkse 1974) of low fertility ( $15 \mathrm{ppm}$ Truog P) and very low resident clover content. Each plot consisted of 10 plants inserted into the browntop-dominant sward in a $1 \mathrm{~m}$ row running down the slope with $60 \mathrm{~cm}$ gaps betwen rows. The trial was a randomized block design with four replicates on each site (aspect).

TABLE 1: ORIGINS, MEAN PLANT TYPE SCORES (1-9), AND MEAN GROWTH SCORES (O-80) IN EACH OF THREE YEARS FOR 98 WHITE CLOVER LINES GROWN AT BALLANTRAE

\begin{tabular}{|c|c|c|c|c|c|}
\hline Origin & $\begin{array}{c}\text { Number } \\
\text { of } \\
\text { Lines }\end{array}$ & $\begin{array}{l}\text { Plant } \\
\text { Type }\end{array}$ & Year 1 & $\begin{array}{c}\text { M ean G rowth } \\
\text { Y ear } 2\end{array}$ & Year 3 \\
\hline New Zealand & 16 & $4.1 \pm 0.1$ & $36 \pm 2.8$ & $31 \pm 2.0$ & $15 \pm 1.4$ \\
\hline Huia & (1) & $5.2 \pm 0.3$ & $44 \pm 8.4$ & $37 \pm 3.5$ & $17 \pm 3.4$ \\
\hline Pitau & (1) & $6.4 \pm 0.3$ & $54 \pm 5.9$ & $38 \pm 3.4$ & $15 \pm 3.7$ \\
\hline Ladino x 4700 & (1) & $6.0 \pm 0.3$ & $39 \pm 3.2$ & $27 \pm 1.2$ & $14 \pm 2.9$ \\
\hline ex Ballantrae & (3) & $2.9 \pm 0.2$ & $24 \pm 1.5$ & $20 \pm 1.6$ & $10 \pm 1.0$ \\
\hline ex Hill Country & (10) & $4.0 \pm 0.1$ & $37 \pm 1.6$ & $34 \pm 1.2$ & $16 \pm 1.1$ \\
\hline Afghanistan & 4 & $2.9 \pm 0.2$ & $15 \pm 3.0$ & $14 \pm 1.7$ & $9 \pm 0.6$ \\
\hline Argen & & $5.4 \pm 0.3$ & $52 \pm 7.3$ & $31 \pm 2.7$ & $8 \pm 1.9$ \\
\hline Belgium & & $5.3 \pm 0.3$ & $43 \pm 3.8$ & $33 \pm 1.5$ & $12 \pm 1.0$ \\
\hline Denmark & 3 & $4.2 \mp 0.2$ & $31 \pm 1.5$ & $20 \pm 1.6$ & $8 \pm 1.0$ \\
\hline France & 8 & $5.0 \pm 0.1$ & $42 \pm 2.4$ & $31 \pm 1.1$ & $12 \pm 0.8$ \\
\hline Germany & 5 & $4.4 \pm 0.1$ & $31 \pm 2.3$ & $19 \pm 1.7$ & $8 \pm 0.8$ \\
\hline Hungary & & $4.6 \pm 0.3$ & $31 \pm 3.2$ & $19 \pm 1.2$ & $9 \pm 1.5$ \\
\hline Iran & 9 & $4.4 \pm 0.1$ & $27 \pm 2.1$ & $20 \pm I .0$ & $8 \pm 0.6$ \\
\hline Israel & 5 & $7.0 \pm 0.1$ & $45 \pm 2.3$ & $22 \pm 1.4$ & $8 \pm 0.4$ \\
\hline Lebanon & & $6.1 \pm 0.3$ & $48 \pm 10.0$ & $27 \pm 3.2$ & $7 \pm 2.6$ \\
\hline Morocco & 1 & $5.7 \pm 0.3$ & $46 \pm 9.9$ & $31 \pm 3.8$ & $8 \pm 1.3$ \\
\hline Netherlands & 2 & $4.3 \pm 0.2$ & $28 \pm 2.2$ & $23 \pm 2.7$ & $10 \pm 0.9$ \\
\hline Norway & & $5.9 \pm 0.3$ & $37 \pm 6.5$ & $22 \pm 2.5$ & $5 \pm 1.2$ \\
\hline Pakistan & & $2.0 \pm 0.3$ & $7 \pm 4.7$ & $11 \pm 3.8$ & $7 \pm 1.0$ \\
\hline Portugal & 7 & $4.9 \pm 0.1$ & $37 \pm 2.5$ & $22 \pm 1.6$ & $7 \pm 0.7$ \\
\hline S & 4 & $3.7 \pm 0.2$ & $25 \pm 2.4$ & $19 \pm 0.9$ & $6 \pm 0.9$ \\
\hline Switzerland & 3 & $4.2 \pm 0.2$ & $32 \pm 2.1$ & $22 \pm 2.8$ & $8 \pm 1.3$ \\
\hline Turkey & 6 & $4.9 \pm 0.1$ & $35 \pm 2.1$ & $21 \pm 1.3$ & $10 \pm 1.2$ \\
\hline United Kin & 4 & $4.0 \pm 0.2$ & $37 \pm 4.3$ & $30 \pm 4.2$ & $8 \pm 1.7$ \\
\hline United States & 12 & $5.5 \pm 0.1$ & $40 \pm 1.8$ & $26 \pm 0.9$ & $11 \pm 0.7$ \\
\hline U.S.S.R & 2 & $3.1 \pm 0.2$ & $18 \pm 1.7$ & $13 \pm 2.2$ & $7 \pm 0.4$ \\
\hline Yugoslavia & & $2.5 \pm 0.3$ & $18 \pm 2.3$ & $12 \pm 1.5$ & $7 \pm 0.4$ \\
\hline
\end{tabular}


During the first September after establishment, each plot was scored for plant type using a 1 to 9 scale; 1 denoting a very smallleaved prostrate type and 9 a large-leaved more erect type. Visual scores for relative growth using a 0 to 10 scale were taken for each row in September, November and January of the first and following 2 years. The area was grazed with sheep, and occasionally cattle, after each growth note, and also once or twice during winter, Throughout the last winter of the trial (1977), the area was set-stocked with sheep for 4 months. Because there were no line $\mathrm{X}$ aspect interactions, the experiment was analysed as a single site with eight replicates.

\section{RESULTS}

Average plant type is summarized in Table 1. Clovers from Mediterranean sources (e.g., Israel, Lebanon, Morocco) were large-leaved, as were the New Zealand cultivar Pitau- and the experimental hybrid line (Ladino X Pitau), both of which have some Mediterranean parentage. Huia was slightly smaller-leaved, 10 New Zealand hill country lines smaller still, and material from Ballantrae smallest-leaved with a mean score of 2.9. Kent wild white clover (U.K.) also showed a mean type score of 2.9.

Plant types are also shown in Fig. 1, which relates growth in the first year with type. The majority of white clover lines in the trial (67 out of 98) were smaller-leaved than Huia. Growth in the first year was significantly correlated with type $(r=0.71, P<$ 0.01 ), larger-leaved lines tending to be better, on average, than those with smaller leaves. For example, of the 27 lines which scored better than Huia, 20 were larger-leaved than Huia. The 10 lines collected from New Zealand hill country farms (shown as open circles in Fig. 1) ranged from very small-leaved types to Huia types and were among the best producers of their types, along with Kent wild white.

In the second year, relative growth scores of most lines declined (Table 1). The relationship between growth and plant type became less marked $(r=0.42, P<0.01)$ as the performances of most of the large-leaved and intermediate types dropped relative to Huia (Fig. 2). Only five lines ranked higher than Huia, two being collections from New Zealand hill country, one Pitau, and two overseas lines - Crau (France) and S. 100 Nomark (U.K.). The New Zealand hill country collections stood out, along with Kent wild white, as being outstanding for their types. 
These trends continued in the third year of the trial. Relative growth scores declined dramatically (Table 1) and there was no longer a correlation between growth and plant type (Fig. 3). Although statistical differences were few, some trends were clear. Seven lines ranked above Huia-Crau (France), a line from New Hampshire (U.S.A.), and five of the New Zealand hill

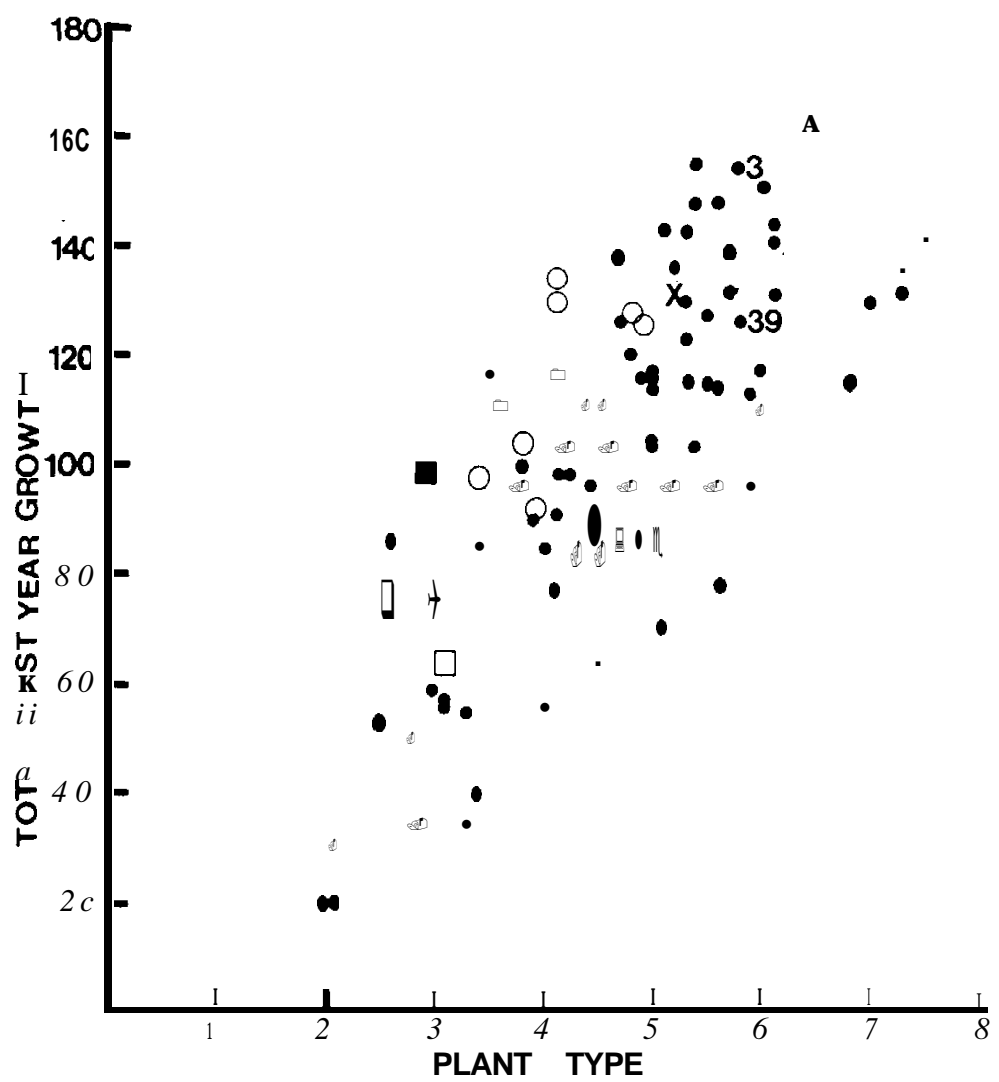

FIG. 1: Relationship between plant type and first-year growth for 98 white clover lines grown at Ballantrae.

o Collections Jrom New Zealand hill country farms

$\square$ Collections from Ballantrae

$\times$ Huia

$\triangle$ Pitau

- Kent wild white

3 Crau (France)

39 ex New Hampshire (U.S.A.)

- All other lines 


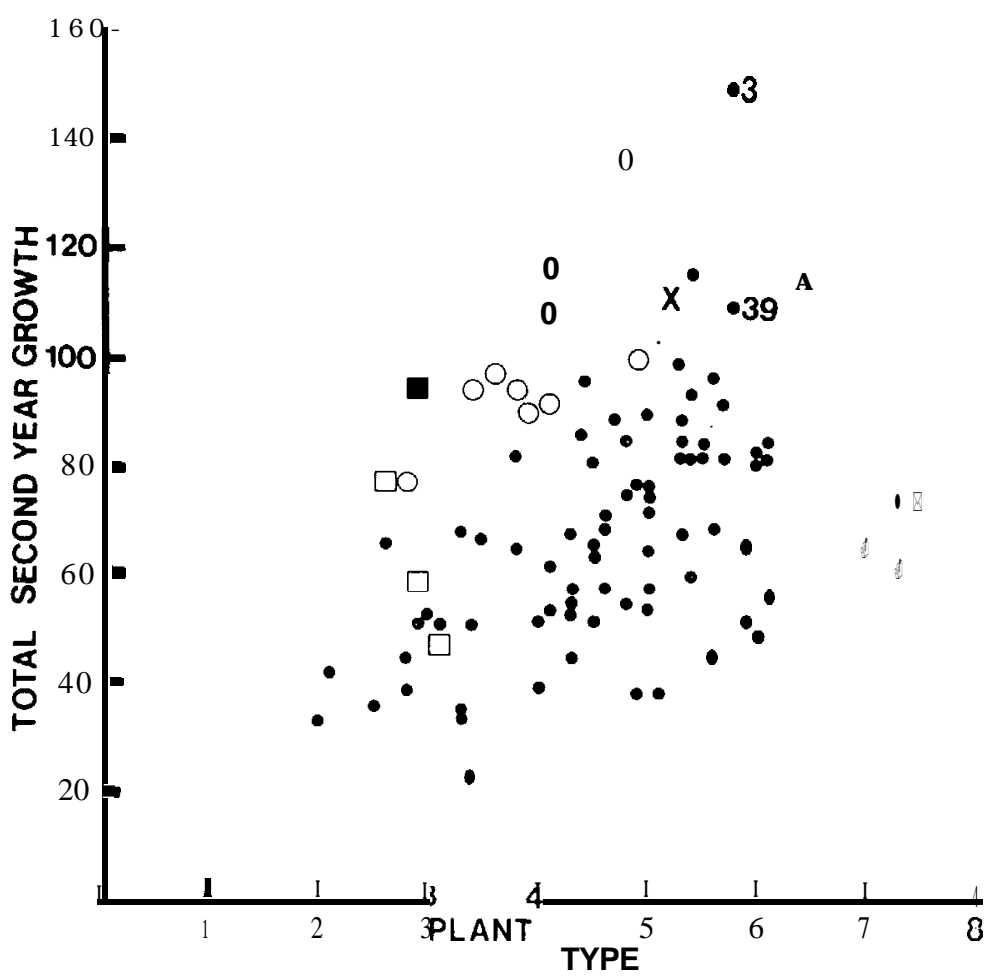

FIG. 2: Relationship between plant type and second-year growth for 98 white clover lines grown at Ballantrae (symbols as in Fig. 1).

country collections. Relative performances of S.100 Nomark, Pitau, Kent wild white and three of the New Zealand lines all declined. The remainder of the New Zealand hill country lines stood out as a group which performed well, although those derived from Ballantrae (the trial site) did not do well at any stage.

The four lines of T. ambiguum showed little growth and, although beginning to show some signs of production by the third year, were still only equivalent at that stage to the poorest white clovers.

\section{DISCUSSION}

Results 'indicated that growth of white clover lines in the first year on low-fertility hill country was related to plant type, large-leaved types performing better, on average, than small-leaved 


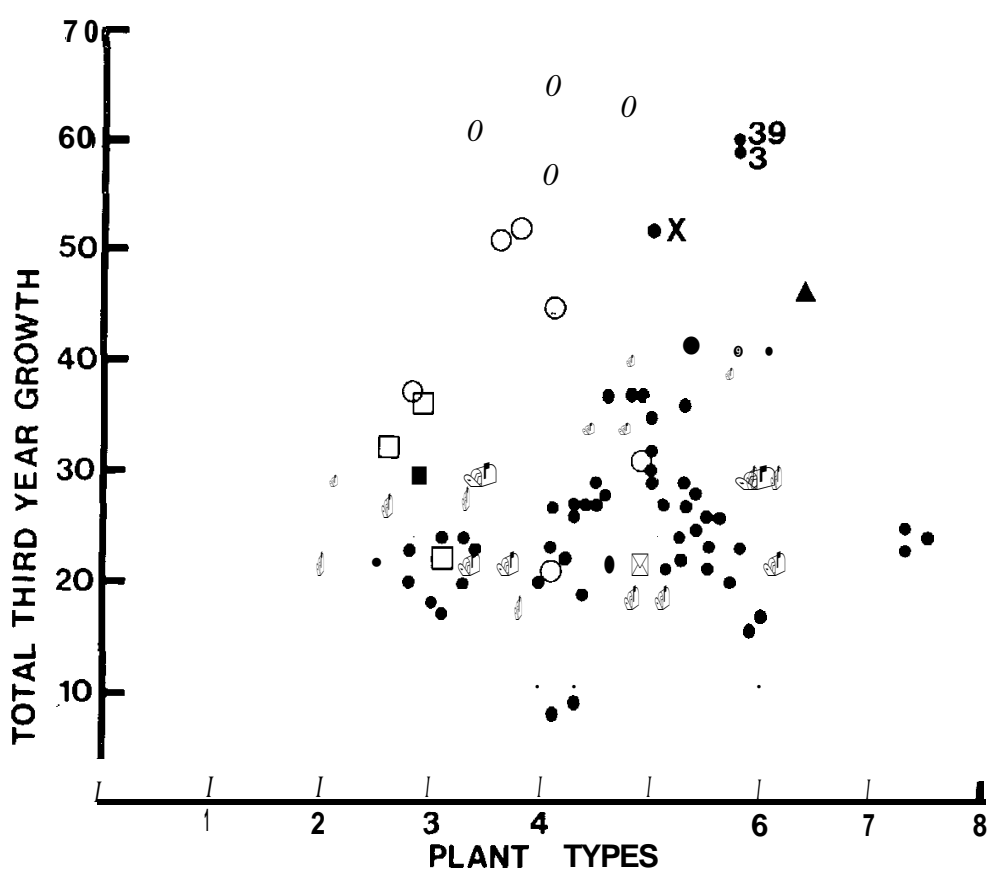

FIG. 3: Relationship between plant type and third-year growth for 98 white clover lines grown at Ballantrae (symbols us in Fig. 1).

types. However, with time and increased grazing pressure the larger-leaved forms, with few exceptions, declined in relative performance, while some smaller-leaved types improved. These shifts in relative performances were consistent with expectations. Correlations between leaf size and early productivity are normal in white clover (e.g., Davies and Young, 1967), while the inability of large-leaved forms to withstand harsh conditions, including sheep grazing, are well documented (e.g., Davies and Levy, 1931; Davies, 1962).

Overseas lines were generally very poor by the third year, with the exception of Crau (France) and a population from New Hampshire (U.S.A.). These were the only lines in the trial which, although initially larger-leaved than Huia, survived for the three years to remain higher ranked at the end. They clearly deserve further investigation.

Davies and Levy (1931) indicated that if the habitat range of white clover were to be extended towards poorer quality soils on which sheep grazing predominated, then Kent wild white 
would probably play a role, Present results have indicated that, while Kent was one of the best performing small-leaved strains early in the trial, it later faded relative to some of the New Zealand hill country collections intermediate in type between Huia and Kent. The origin of these hill country strains is unknown, but their intermediate nature could indicate that they have developed under natural selection after crossing of Kent types sown in the "bush-burn" days with later oversown "pedigree" white clover of Huia type, Other New Zealand hill country collections, including those from the trial site, Ballantrae, did not perform well. With the exception of two, these were in the same leaf-size class as Kent.

Although Huia performed well, its ability to withstand many years of sheep grazing on low-fertility hill country is uncertain. Davies and Levy (1931) warned that high fertility-adapted strains would not do as well on low-fertility soils as those adapted to poorer habitats. The results of Forde and Suckling (1977) are consistent with this warning. They showed that little or no pedigree-type white clover existed in pastures at Te Awa which had been oversown 25 years earlier. The failure of Huia to persist in low-fertility conditions under sheep grazing warrants further investigation.

Snaydon and Bradshaw ( 1962) and Bradshaw (1969) have shown in Britain that lowland populations of white clover did not survive in upland pastures where nutrient levels were low. However, plants collected from low-fertility upland sites did survive. When fertilizer was added, the lowland plant survival improved, indicating that the populations differed in their abilities to survive at low fertility. Competition was also shown to be a factor in the poor performance of lowland plants in hill pastures.

Present results indicate that white clover strains occurring on New Zealand hill country farms are variable and some show considerable promise for use under low-fertility conditions with sheep grazing. A plant breeding programme using these populations as source material to develop a cultivar bred especially for New Zealand hill country is justified.

\section{ACKNOWLEDGEMENTS}

Most of the overseas lines tested in this trial were supplied by F. W. Hely, CSIRO, Canberra, and most of the New Zealand collections were made by F. E. T. Suckling, Grasslands Division, Palmerston North. We gratefully acknowledge these contributions. 